\title{
Turismo cultural e educação \\ patrimonial: conscientizar sobre \\ a importância da preservação
}

\section{Paulo de Assunção*}

assuncao@prestonet.com.br

\section{Resumo}

Este artigo tem como objetivo apresentar o processo de discussão sobre a relação entre turismo cultural, patrimônio e educação patrimonial. A partir da década de 1980, o turismo cultural ganhou contornos claros como produto turístico, sendo possível identificar que a motivação da viagem tinha como objetivo principal conhecer a cultura ou patrimônio de um determinado destino/cidade. Essa caracterização fez com que esse segmento passasse paulatinamente a ser reconhecido como uma atividade de grande potencial e recebesse estudos mais aprofundados. Nos debates recentes, é evidenciada a importância da criação de uma legislação abrangente protetora e estimuladora do turismo cultural e da educação patrimonial a fim de criar uma cultura de conscientização sobre a importância da preservação do patrimônio.

\section{Palavras-chaves}

Turismo; Patrimônio; Cultura

Cultural tourism and patrimonial education: raising awareness about the importance of preservation

\begin{abstract}
This article aims to present the process of discussion about the relationship between cultural tourism, patrimony and patrimonial education. From the $1980 \mathrm{~s} \mathrm{cul}$ tural tourism gained clear contours as a tourist product, being possible to identify that the motivation of the trip had as main objective to know the culture or patrimony of a certain destination/city. This characterization made this segment gradually to be recognized as an activity of great potential and to receive more in-depth studies. Recent debates have highlighted the importance of creating a comprehensive protective and stimulating legislation for cultural tourism and heritage education in order to create a culture of awareness of the importance of preserving heritage.
\end{abstract}

\section{Keywords}

Tourism; Patrimony; Culture

\footnotetext{
*Universidade Estadual de Maringá (UEM). Bolsista produtividade do Conselho Nacional de Desenvolvimento Científico e Tecnológico.
} 
No decorrer da última década do século XX novos estudos são realizados referentes ao turismo cultural, tendo em conta o crescimento dessa prática, o que exigiu a precisão de uma terminologia específica. A European Association for Tourism and Leisure Education (ATLAS), a partir da contribuição feita por Greg Richards, entendeu que dois tipos de definições poderiam ser atribuídos ao "turismo cultural”, uma conceitual e outra técnica. A definição conceitual entendia que o termo expressava: "el traslado temporal de personas a uma atracción cultural lejos de su residência habitual com la intención de satisfacer sus necessidades culturales". A definição técnica do termo seria: "todos los traslados de personas a uma atracción cultural específica, tales como, lugares patrimoniales, muestras artísticas y culturales, arte y teatro, fuera de su lugar habitual de residência". Ambas as definições conseguiam captar a dimensão do turismo cultural nas suas diferentes manifestações e serviriam para reflexões futuras. (RICHARDS, 1996, p. 24)

Greg Richards ressaltava que o turismo cultural era um conceito abrangente que abarcava, até aquele momento, o que era designado de "turismo patrimonial”. Esse, por sua vez, estava ligado tanto aos artefatos feitos no passado, como também ao que era chamado "turismo artístico", o qual estava diretamente relacionado à produção cultural contemporânea. (RICHARDS, 2001, p. 7) O autor nas suas reflexões se valeu dos debates que estavam em voga sobre turismo e patrimônio, os quais evidenciavam a necessidade de políticas públicas que levassem em consideração os dois temas.

\section{Em 1991, realizou-se o I Colóquio Internacio-} nal das Cidades do Patrimônio Mundial, no Canadá, reunindo delegados que representavam mais de quarenta cidades incluídas na Lista do Patrimônio. O produto deste encontro foi a adoção da Carta para a Preservação do Patrimônio do Quebec, adotada pelo ICOMOS de Canadá, posteriormente conhecida como Carta de Quebec. Esse documento tinha como objetivo tentar identificar a personalidade cultural do Quebec, ao mesmo tempo que encorajava as pessoas a pensarem antes de agirem respeitando o patrimônio. $\mathrm{O}$ documento entendia patrimônio como

as criações e os produtos da natureza e do homem, combinados, e na sua integridade, que constituem, no espaço e no tempo, o ambiente em que vivemos. $O$ patrimônio é, na realidade, um bem, propriedade da comunidade, e uma herança rica que pode ser deixada para o futuro, que convida ao nosso reconhecimento e à nossa participação. (ICOMOS - Carta para a Preservação do Patrimônio do Quebec - Declaração de Deschambault, 1982)

O conceito bem amplo apresentado entendia que o patrimônio do passado deveria ser utilizado para construir o patrimônio do futuro, dando relevo importante para a paisagem cultural, a qual é o resultado da interação entre a sociedade humana e a natureza. $\mathrm{O}$ documento entendia que os cidadãos tinham, em primeiro lugar, uma responsabilidade individual pela proteção do seu patrimônio, ele era um tesouro que pertencia à comunidade e não era renovável. $\mathrm{O}$ reconhecimento do patrimônio era um pré-requisito essencial para a sua preservação, sendo importante que ele tivesse reconhecimento público. (ICOMOS - Carta para a Preservação do Patrimônio do Quebec - Declaração de Deschambault, 1982).

\section{O II Colóquio Internacional das Cidades do} Patrimônio Mundial (1993) reuniu delegados que representavam cinquenta e seis cidades, os quais determinaram pela fundação da Organização das Cidades do Patrimônio Mundial (OCPM). A ação da OCPM teve por objetivo contribuir para a implantação da Convenção do Patrimônio Mundial. Era consenso que um dos pontos estratégicos para garantir a preservação do patrimônio era a formação de gestores capazes de conduzi- 
rem ações de valorização e de conservação dos conjuntos históricos e a proteção das cidades históricas, frente as ameaças do desenvolvimento acelerado das cidades contemporâneas.

No que diz respeito à atividade turística, foi importante a definição realizada pela Declaração de Querétaro (1993), a qual avançou nos debates sobre a relação do patrimônio com a atividade turística, sendo reafirmada a importância de ações de planejamento, conservação e manutenção do patrimônio. Como podemos notar, há uma preocupação em alinhar debates entre a questão do patrimônio e o fenômeno turístico em âmbito mundial. (ICOMOS - Declaração de Querétaro, 1993)

Em 1994, foi elaborada a Declaração de Osaka para o milênio que discutia a questão do patrimônio e do turismo, apontando a importância do enriquecimento pessoal com o conhecimento de outras culturas, bem como os impactos que a atividade turística poderia ter sobre as comunidades receptoras. Nesse mesmo ano, acontecia a Conferência de Nara, sediada no Japão, que teve como foco debater os meios para ampliar os horizontes no que concernia à preservação da diversidade do patrimônio cultural na prática da conservação. Os estudiosos reunidos chamavam a atenção para o processo da globalização, o qual comprometia diretamente a identidade cultural. Era preciso aprofundar as análises para reforçar o valor de autenticidade na prática da conservação, como forma de "iluminar a memória coletiva da humanidade". Não poderia ser esquecido que as tradições culturais eram uma realidade no tempo e no espaço e exigiam respeito e cuidado especiais, diante do processo de homogeneização cultural. Os governos deveriam atentar para a importância de que no interior de cada cultura, "o reconhecimento da mesma estivesse de acordo com a natureza específica de seus valores patri- moniais e veracidade das pesquisas relacionadas". (IPHAN, Conferência de Nara, 1994, p. 2-3)

$\mathrm{O}$ assunto também foi debatido pelo Parlamento Europeu, que elaborou o Livro Verde sobre El Papel de la Unión Europea en Materia de Turismo ${ }^{1}$. Esse documento foi um passo importante na medida em que fazia propostas de ações para que os países membros da União Europeia atuassem de forma conjunta em relação ao patrimônio e ao turismo, defendendo uma política turística integrada. Aproveitando as reflexões dos especialistas, foi elaborada a Resolución del Parlamento Europeo Sobre el Turismo en el Horizonte 2000, tendo como objetivo facilitar o conhecimento do patrimônio por meio de projetos eletrônicos de informação turística, dentre outras ações.

O debate sobre patrimônio se intensificava e, em 1995, realizou-se o III Colóquio Internacional das Cidades do Patrimônio Mundial, na Noruega, que tinha como desafio estabelecer uma comunicação mais eficaz entre as Cidades do Patrimônio Mundial, a fim de que experiências e soluções, no âmbito da valorização e preservação, fossem compartilhadas. Nesse momento, também aconteceu a Conferência Mundial de Turismo Sustentável que aprofundou a discussão sobre a questão da sustentabilidade, a qualidade de serviços e a necessidade de políticas turísticas. Ao final do evento, foi apresentada a Carta do Turismo Sustentável de Lanzarote (1995), que constitui um marco no desenvolvimento turístico. (OMT - Carta do Turismo Sustentável, 1995). Podemos afirmar que era reafirmado o compromisso da atividade turística com a preservação do meio ambiente e da cultura local, defendendo a prioridade do desenvolvimento sustentável. (HENRIQUES, 2003, p. 213)

O Conselho da Europa, também no ano de 1995, elaborou a Recomendação Europa que discorria sobre a

\footnotetext{
${ }^{1}$ Consultar sobre este livro e demais: Disponível em: $<$ http://europa.eu/rapid/press-release_IP-10-858_es.htm>. Acesso em: 11/04/2017.
} 
conservação integrada das áreas de paisagens culturais como integrantes das políticas paisagísticas. A relação desequilibrada dos indivíduos com o meio ambiente poderia causar:

- uso insustentável de recursos naturais do solo, subsolo, água e atmosfera;

- desenvolvimento descontrolado dos setores da indústria, energia, turismo e lazer;

- intensificação exagera e altamente especializada da agricultura e a silvicultura, acompanhada de objetivos que não levam em conta a terra e o despovoamento rural;

- desenvolvimento urbano insuficiente planejado e executado, sobretudo nas zonas suburbanas;

- instalação de grandes construções ou infraestrutura de transportes sem a necessária avaliação a respeito do caráter e da qualidade das áreas em que estão situadas;

- negligência ou inadvertência sobre o valor das paisagens culturais, devidas à falta de informação e educação. (IPHAN -Recomendação Europa, 1995, p. 4)

Tais problemas deveriam ser identificados e inibidos pelos governos nas suas políticas de planejamento urbano e turístico. O documento fornecia orientações sobre o processo de identificação e de avaliação das áreas de paisagem natural, os níveis de competência e as estratégias de ação no contexto das políticas de paisagem. Alertando para o fato da necessidade da proteção legal e conservação das áreas de paisagem cultural.

No Brasil, foi elaborada a Carta de Brasília (1995), que afirmou a necessidade de preservação da autenticidade dos povos latino-americanos e a contribuição das diferentes tribos indígenas que, nas suas configurações diversas, moldaram os povos que habitam a América Latina, deixando legados e heranças ímpares. A identidade era definida como "uma forma de pertencer e participar", entendendo que ela era dinâmica e mutável e que poderia adaptar-se face às novas necessidades. (IPHAN - Carta de Brasília - 1995, p. 2.) No que dizia respeito à conservação da autenticidade dos conjuntos urbanos com um valor patrimonial, pressupunha-se a manutenção do seu conteúdo sociocultural, "melhorando a qualidade de vida de seus habitantes, é imprescindível o equilíbrio entre o edifício e seu entorno, tanto na paisagem urbana quanto na rural. Sua ruptura seria um atentado contra a autenticidade". (IPHAN - Carta de Brasília - 1995, p. 4) Para a efetivação destas intenções, era preciso criar normas especiais voltadas para manter o equilíbrio dos espaços.

O ICOMOS, na sua XI Assembleia Geral, elaborou a Declaração de Sofia (1996), que defendia o pluralismo cultural e o respeito ao patrimônio alheio e o repúdio a qualquer ato de intolerância por parte de grupos radicais. A crise econômica, que se abatia sobre algumas regiões do planeta, apontava para o fato de que o patrimônio cultural enfrentaria desafios que poderiam ameaçar a sua integridade. Discutia-se que a atividade turística não poderia pretender utilizar-se do patrimônio, assegurando apenas o respeito ao seu significado e à sua mensagem. Para que a preservação continuasse, era preciso a realização de "estudos analíticos e inventários completos, como o objetivo de explicitar os diversos significados do patrimônio no mundo contemporâneo e justificar as novas modalidades de uso a que se propõem”. (IPHAN - Declaração de Sofia,1996, p. 2) Mais uma vez era reforçada a ideia de que a atividade turística deveria ser planejada, e que um dos pontos a ser considerado no planejamento era o uso adequado do patrimônio.

No ano seguinte, foi realizado, em Portugal, o IV Colóquio Internacional das Cidades do Patrimônio Mundial, o qual revisitou o tema, enfatizando os debates em relação à atividade turística e as cidades históricas. A OMT defendeu a importância do turismo no processo para garantir a continuidade da preservação e valorização do patrimônio. Era fundamental a realização de estudos que avaliassem o impacto turístico sobre a população que habitava uma cidade, bem como monu- 
mentos e sítios históricos. Essas informações norteariam os estudos de diagnósticos a serem realizados visando à preservação do patrimônio. (HENRIQUES, 2003, p. 216)

Neste mesmo ano, no Brasil, o IPHAN promoveu na cidade de Fortaleza, o Seminário Patrimônio Imaterial: Estratégias e Formas de Proteção. O Seminário reuniu especialistas dos patrimônios nacionais e internacionais, de diferentes instituições, inclusive da UNESCO, que debateram aspectos que envolviam a identidade cultural e a memória dos diversos grupos étnicos formadores da sociedade brasileira, dando especial atenção aos modos de criar, fazer e viver, em especial aqueles referentes à cultura popular. (SIMÕES, 2009, p. 49-67) O objetivo do Seminário era coletar informações e dados que permitissem a elaboração de diretrizes que possibilitassem a criação de leis que protegessem, promovessem ou fomentassem os bens culturais de referência à identidade nacional, considerando os grupos formadores da sociedade brasileira, conforme o que determinava a Constituição Brasileira de 1988. A Carta de Fortaleza, elaborada ao final do seminário, apresentou recomendações, considerando a necessidade de reconhecimento e preservação do patrimônio cultural brasileiro, constituído por bens de natureza material e imaterial, bem como o papel do IPHAN, enquanto instituição responsável para proteger, fiscalizar, preservar o patrimônio nacional. $\mathrm{O}$ documento chegava às seguintes definições: o IPHAN era responsável por promover debates sobre o conceito de bem cultural de natureza imaterial; o IPHAN deveria realizar inventários desses bens culturais em âmbito nacional, em especial sobre as quais já existam informações disponíveis; os inventários deveriam ser disponibilizados e integrados ao Sistema Nacional de Informações Culturais; a criação de grupos de trabalho, sob coordenação do IPHAN, a fim de propor instrumento legal para registro e preservação dos bens culturais de natureza imaterial; a pro- moção e proteção dessas manifestações culturais; a preservação do patrimônio cultural deveria ser abordada de maneira global, buscando valorizar as formas de produção simbólicas e cognitivas; desenvolver um Programa Nacional de Educação Patrimonial e uma Política Nacional de Preservação do Patrimônio Cultural. A Carta de Fortaleza reafirmou a importância da legislação de preservação existente, e a criação de leis complementares, sendo destacado o apoio e reconhecimento das atividades exercidas pelo IPHAN; a defesa à Lei de Incentivo à Cultura; o apoio às expressões culturais dos povos ameríndios, como integrante do patrimônio nacional brasileiro, p. 3-4)

O que se pode identificar é um processo de debates intensos que visava a criar diretrizes para a preservação do patrimônio de forma harmônica com a atividade turística, para garantir o benefício de todos os setores da sociedade. Isso fazia com que uma questão fosse abordada: a educação patrimonial. (GRUNBERG, 2007)

O sociólogo Pierre Bourdieu, por meio dos seus estudos, discutiu as necessidades, as práticas e as preferências culturais dos indivíduos e da sociedade resultavam da educação. Alertava para o fato que o rendimento, a ocupação profissional, o tempo livre, a idade, etc., influenciavam diretamente nas práticas culturais. Caberia ao Estado e às sociedades eliminarem as barreiras para a participação cultural, o que, em última instância, significaria a possibilidade de aumento da atividade turística. (BOURDIEU, 1979)

O pensador Jacques Delors, por sua vez, afirmava que somente a educação conduziria a um desenvolvimento harmonioso que faria recuar a pobreza, a exclusão social e as incompreensões que conduziam às diversas guerras em curso. (DELORS, 1999, p. 89-102)

Havia um consenso de que o turismo cultural emergiria como decorrência do processo de inclusão social e de desenvolvimento das sociedades. Tal situa- 
ção fazia com que a educação patrimonial fosse uma das metas da educação contemporânea e dos órgãos ligados à preservação do patrimônio. Era por meio de um amplo processo de sensibilização que seria possível mostrar a importância do patrimônio cultural para a humanidade, a fim de que este fosse respeitado, preservado e valorizado. (HORTA, [s.d.])

A educação patrimonial tinha como uma das suas premissas a conscientização do indivíduo. Era fundamental consolidar a ideia de que todos eram agentes histórico-sociais responsáveis pela preservação e manutenção da memória coletiva. Por decorrência, era importante que os indivíduos apreendessem o significado deste patrimônio na sua trajetória histórico-temporal e soubessem interagir com ele, sendo capazes de definir o que é ou não é patrimônio. Isto permitiria que eles assimilassem a importância do monumento, objeto, tradição, etc., para a sua existência e identidade, bem como para a das gerações futuras. A aproximação do indivíduo com o patrimônio contribuía para a formação de um cidadão consciente dos seus direitos e deveres, capaz de compreender a importância da preservação dos bens culturais para a preservação da memória e da identidade de um povo ou nação.

O processo de educação patrimonial deveria instigar o indivíduo a: observar e pensar sobre o bem cultural; a manifestar quais as impressões sobre o bem cultural; a pesquisa e a discussão dos resultados; e a apropriação do significado do bem para cada um. A educação patrimonial poderia estimular visitas aos museus, exposições, monumentos e outras atividades que alargassem o repertório de conhecimento dos indivíduos.

A veiculação de material informativo impresso, os meios de comunicação, a realização de eventos, seminários e exposições, a publicação de livros, revistas e cartilhas, a produção de vídeos e outros materiais, como também o desenvolvimento de ações educativas, eram meios importantes para divulgação da importân- cia do patrimônio. (BARRETO, 2000, p. 55)

Nos debates realizados em 1997, os técnicos do IPHAN deram atenção especial à educação patrimonial. Partiam do pressuposto de que toda e qualquer ação do IPHAN tinha um caráter educativo, capaz de determinar o comportamento dos indivíduos e das coletividades. Uma das conclusões do grupo foi a definição pela implantação de um Programa de Educação Patrimonial, nas unidades do IPHAN. Também seria elaborado um Guia Básico de Educação Patrimonial, contendo desde conceitos até metodologias para desenvolvimento de atividades. (HORTA, [s.d.]) As políticas do órgão estimulariam projetos de Educação Patrimonial, em suas unidades e também levantaria linhas de financiamento para efetivar a divulgação do patrimônio. Os técnicos entendiam que os principais objetivos da educação patrimonial eram: tornar acessível aos indivíduos os instrumentos e a leitura crítica dos bens culturais; fortalecer a identidade cultural; estimular a apropriação, o uso e a responsabilidade da comunidade pelo patrimônio cultural; estimular a interação entre a sociedade e os órgãos responsáveis pela identificação, proteção e promoção do patrimônio cultural e promover a produção de novos conhecimentos sobre a dinâmica cultural.

A educação patrimonial era o meio mais adequado de conscientizar a população para a importância da preservação, pois a utilização do patrimônio cultural ou natural permitia que muitas comunidades tivessem um desenvolvimento sustentável, o qual garantiria a geração de renda para toda a população. Entendia-se que era vital que a população precisava estar engajada nas ações de preservação dos bens culturais e naturais, visando à preservação de uma memória coletiva que era importante para a manutenção dos valores do grupo e da sua transmissão e continuidade para as gerações futuras, que deveriam aprender a valorizar este patrimônio. Reforçava-se a ideia de que o patrimônio constituía 
uma herança histórica, deixada pelas gerações anteriores, cabendo a todos preservar para que fosse transmitido as gerações vindouras. O patrimônio era o testemunho vivo da diversidade cultural realizado pelos homens em diversas épocas e que deveria ser preservado para que os nossos descendentes pudessem apreciar e avaliar o desenvolvimento da humanidade.

Nesse mesmo ano, aconteceu a I Jornada do Mercosul sobre Patrimônio Intangível, que deu origem à Carta de Mar Del Plata sobre Patrimônio Intangível, alargando, ainda mais, os debates sobre cultura. Os princípios definidos reforçavam a ideia da integração cultural, que deveria contar com respaldo político dos governos. A integração dos países da América do Sul pressupunha a aceitação da pluralidade étnica e cultural e o estímulo ao desenvolvimento humano. Tendo em vista a carência de estudos, era aconselhado que ações como a elaboração de inventários, políticas culturais específicas, cursos de formação e de educação patrimonial deveriam ser empreendidos pelos governos. Esses eram os responsáveis por fomentar a articulação de ações para a preservação patrimonial e turismo, visando ao desenvolvimento social produtivo. (IPHAN - Carta de Mar del Plata sobre patrimônio intangível, 1997, p. 2-4)

No contexto brasileiro, é delineado de forma mais precisa o papel do IPHAN. Pelo decreto $n^{\circ}$. 2807, de 21 de outubro de 1998, aprovou a estrutura regimental do IPHAN, confirmando que sua finalidade é pesquisar, promover, fiscalizar e proteger o patrimônio cultural. É de competência do órgão:

formular e coordenar a execução da política de preservação, promoção e proteção do patrimônio cultural, em consonância com as diretrizes do Ministério da Cultura; formular e promover programas de cooperação técnica e aperfeiçoamento de recursos humanos para conservação $e$ preservação do patrimônio cultural. ${ }^{2}$

Para que a política de proteção do patrimônio se consolidasse o IPHAN deveria promover estudos e pesquisas, que contribuíssem para a conservação e preservação dos bens materiais e imateriais; ao mesmo tempo, deveria promover o inventário e identificação do patrimônio, "realizando a documentação, o registro, a difusão, a vigilância, o tombamento, a desapropriação, a conservação, a restauração, a devolução, o uso e a revitalização do patrimônio cultural". Além disso, cabia ao órgão zelar pelo patrimônio atentando para os usos que a atividade turística poderia fazer deles, dentro dos limites que os bens culturais não ficassem comprometidos, e nos casos que se fizessem necessários utilizar das normas legais vigentes. Esse realinhamento foi importante para se definirem as diretrizes a serem seguidas no século XXI.

O V Colóquio Internacional das Cidades do Patrimônio Mundial, realizado na Espanha, em 1999, discutiu temas correlatos à inovação da gestão das cidades do patrimônio mundial, sendo a questão da educação patrimonial alçada para um lugar de destaque. Foi também confirmada a questão do planejamento da conservação do patrimônio e o seu uso responsável. O passado recente mostrava as dificuldades de aportes dos recursos públicos para fim de preservação, sendo necessário que fossem empreendidas medidas que favorecessem a intervenção da iniciativa privada na recuperação do patrimônio.

\section{A Nova Carta Internacional sobre o Turismo} Cultural - Gestão do Turismo em Lugares de Significação Patrimonial (1999) dedicou especial atenção ao fato de que a atividade era responsável por promover benefícios para a comunidade anfitriã e reforçava a impor-

${ }^{2}$ Decreto Lei ${ }^{\circ}$. 2807, de 21 de outubro de 1998. Atualmente é válido o Decreto no 4.811, de 19 de agosto de 2003. 
tância da parceria entre turismo e patrimônio. Confirmava a necessidade de se criarem mecanismos de reinvestimento das receitas obtidas pelo turismo na conservação e na preservação dos locais turísticos. O documento entendia que os patrimônios natural e cultural pertenciam à coletividade e que deveria ser compreendido como "paisagens, locais históricos, sítios e ambientes construídos, bem como a biodiversidade, coleções, práticas culturais passadas e continuadas, conhecimentos e experiências vividas". O patrimônio era a memória coletiva de uma comunidade, tendo essa a responsabilidade de conservar e gerir o mesmo. Enfatizava -se que o turismo era o meio pelo qual as trocas culturais se processavam, sendo apreciado por muitos e exercia "uma força positiva para a conservação natural e cultural". Os objetivos da Carta Internacional do Turismo Cultural eram "facilitar e encorajar as pessoas envolvidas na conservação e na gestão do patrimônio a tornarem o significado desse patrimônio acessível à comunidade residente e aos visitantes". Era também necessário estimular todos os envolvidos com a atividade turística a promoverem e a gerirem o turismo, de maneira que ele valorizasse o patrimônio e as culturas vivas das comunidades residentes. A facilitação do diálogo entre os interesses da conservação e do turismo era vital para atingir as práticas de sustentabilidade. Por decorrência, era preciso que fossem formulados planos e políticas "para o desenvolvimento de objetivos pormenorizados e mensuráveis, e de estratégias relacionadas com a apresentação e a interpretação dos sítios patrimônio e das atividades culturais, no contexto da sua preservação e conservação". O documento também dava apoio às iniciativas do ICOMOS, de organismos internacionais e do trade turístico na manutenção da integridade da gestão e da conservação do patrimônio. (ICOMOS - Carta Internacional do Turismo cultural 1999, p. 2-4)
Mediante isso, podemos dizer que os princípios norteadores do turismo cultural entendem que o patrimônio tem de ser acessível ao público em geral, sendo que os programas estabelecidos para a proteção e conservação deveriam facilitar uma compreensão e uma apreciação do significado do patrimônio, não só no momento atual como também em longo prazo. Era conveniente que o visitante fosse informado (educação patrimonial) sobre os diferentes valores culturais que poderiam estar associados a um recurso de patrimônio. Dever-se-ia estar atento ao equilíbrio entre o estilo de vida da comunidade residente e as aspirações dos visitantes, considerando que a relação entre patrimônio e turismo era dinâmica. (HENRIQUES, 2003, p. 194)

Os programas estabelecidos para visitantes deveriam interpretar a autenticidade dos sítios e das experiências culturais, a fim de valorizarem a apreciação e a compreensão desse patrimônio cultural. Além disso, era preciso que as intervenções, que viessem a ser feita, levassem em consideração "as características estéticas, as dimensões social e cultural, as paisagens natural e cultural, a biodiversidade e o contexto visual alargado dos sítios patrimônio". Conforme prescrevem as normas internacionais de restauro e conservação, dever-seia dar "preferência à utilização de materiais locais e devem ser tomados em consideração os estilos arquitetônicos locais ou as tradições vernáculas". Cada possibilidade seria estudada nos planos de gestão dos valores naturais e culturais, e caso fosse necessário, dever-se-ia estabelecer limites para evitar o impacto do número de visitantes "sobre as características físicas, a integridade, a ecologia e a biodiversidade do sítio, para o acesso ao local e sobre os sistemas de transporte, e sobre o bem estar social, econômico e cultural da comunidade residente". (ICOMOS - Carta Internacional do Turismo cultural - 1999, p. 5)

Por conseguinte, ficava evidente que o turismo cultural deveria ser capaz de criar um grau de consciên- 
cia sobre o valor do patrimônio e a maneira correta de usufruir dele. $\mathrm{O}$ respeito aos valores e aos estilos de vida de uma comunidade era fundamental ser empreendido. A população local participar do processo de planejamento, discutindo as melhores formas de apresentar o patrimônio e de gerir os recursos culturais, de forma que fossem beneficiados pela atividade turística. (BOYER, 2000, p. 115-127)

A OMT, na sua Assembleia de 27 de setembro a $1^{\circ}$ de outubro de 1999, aprovou um Código de Ética que possuía nove artigos que norteavam as regras para os destinos turísticos que deveriam ser levados em conta por todo o trade turístico, governos e instituições ligadas ao setor. As orientações levavam em consideração as novas formas de turismo ligadas à natureza, entendendo que essas poderiam ser exploradas, desde que se respeitassem os ambientes naturais, e que associassem a população local ao seu desenvolvimento e fosse ajustada à capacidade de ocupação dos lugares turísticos. Era recomendado que o patrimônio cultural recebesse recursos das verbas provenientes das visitas aos locais e monumentos de interesse cultural, que deveriam ser destinados à manutenção, melhoria e valorização do patrimônio. Tal medida fazia com que a atividade turística gerasse impactos econômicos, sociais e culturais positivos, além de fornecer orientações sobre os efeitos sociais e ambientais negativos. (OMT - CódigoMundial de Ética do Turismo, 1999)

No documento O Turismo, fator de preservação do Patrimônio Mundial para o próximo milênio elaborado pela UNESCO (1999) era ressaltada a importância das parcerias entre o poder público e empresas privadas de forma a que fosse possível potencializar as contri- buições positivas e minimizar os impactos sobre o meio cultural. (CAMARGO, 2009, p. 69-88) No mesmo ano é definido o Regulamento de Comunidade Europeia $n^{\circ}$ 1260/1999, que considerava que o desenvolvimento cultural, bem como a "qualidade do ambiente construído e natural e a dimensão cultural e qualitativa da vida e o desenvolvimento do turismo contribuem para que as regiões sejam economicamente e socialmente mais atraentes", pois poderiam incentivar a "criação de empregos sustentáveis"3. Em seguida, o Parlamento Europeu elaborou outro regulamento, de $n^{\circ} 1783 / 1999$, que destacava a importância do desenvolvimento do turismo e dos investimentos culturais para a proteção do patrimônio cultural e natural ${ }^{4}$. Naquele momento discutia-se que a cultura seria o elemento de coesão e desenvolvimento territorial equilibrado.

Em 14 de fevereiro de 2000, o Parlamento Europeu, por meio do seu Conselho, divulgou O Programa Cultura 2000 (Decisão 508/2000/CE)concebido para o período de 2000 a 2004, tendo como foco ações no âmbito do turismo cultural. O programa apresentava ações de cooperação que estimulavam e divulgavam: o conhecimento da história, a criação e difusão da cultura e do patrimônio dos povos europeus, a mobilidade dos artistas e suas obras.

Avançando nos debates sobre o patrimônio mundial, foi realizado em 2001, no México, o VI Colóquio Internacional das Cidades do Patrimônio Mundial. $\mathrm{O}$ evento teve o tema Medidas de prevenção e proteção para as cidades do patrimônio mundial em caso de desastre. Esse tema era recorrente uma vez que os atentados cometidos contra os EUA, em 11 de setembro do mesmo ano estavam em foco. (LANGLEY, 2006)

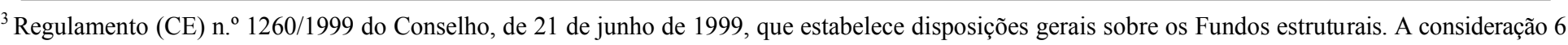
destaca: "Considerando que o desenvolvimento cultural, a qualidade do meio ambiente natural e humanizado, a dimensão qualitativa e cultural da vida

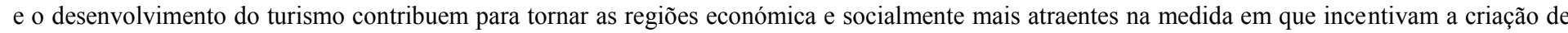
empregos duradoiros".

${ }^{4}$ Regulamento (CE) n 1783/1999 do Parlamento Europeu e do Conselho de 12 de Julho de 1999, relativo ao Fundo Europeu de Desenvolvimento Regional.
} 
As recomendações delineadas pelo documento se atinham à conservação das cidades e dos bairros históricos e permanente manutenção das áreas edificadas. A utilização desses locais, adaptado às condições contemporâneas de infraestrutura, deveria ser feita após um estudo detalhado para que as funções principais não fossem alteradas. Caso ocorressem transformações dos imóveis, como reformas ou acréscimos, sempre deveria ser respeitada a organização espacial existente e a harmonia do conjunto. Era aconselhável que se atentasse para a circulação de veículos que deveria ser regulamentada, bem como as áreas de estacionamento planejadas para que garantissem o entorno do local.

Os órgãos ligados ao patrimônio também evidenciaram o crescimento do número de museus (como os ecomuseus), de centros culturais e de outros tipos de núcleos que apoiavam manifestações artísticas, o que era revelador de um novo momento para o patrimônio e as mudanças que estavam em curso na sociedade. (VASCONCELLOS, 2006, p. 31-46) A conservação e a preservação de cidades, que valorizavam os atrativos culturais e a história viva, em bairros e zonas específicas, possibilitavam uma nova relação do visitante com a cultura. Era cada vez mais rotineiro que a ambientação e representação de cenas históricas se fizessem comuns em cidades históricas e vilarejos, bem como em museus, que procuravam atrair o público de forma diferenciada. O século XXI apontava para o fato que se vivia um momento de exploração do patrimônio de forma que as novas atrações turísticas fossem mais interessantes ao turista contemporâneo, que poderia melhor apreciá-las. (CHOAY, 2001)

Os debates avançaram e, em 2002, foi elaborada a Declaração Universal sobre a Diversidade Cultural que discorreu sobre o crescimento do nível de educação oferecido e seu impacto no aumento do movimento turístico. O documento destacava que:
A cultura adquire formas diversas através do tempo e do espaço. Esta diversidade se manifesta na originalidade e na pluralidade das identidades que caracterizam os grupos e as sociedades que compõem a humanidade. Fonte de intercâmbios, de inovação e de criatividade, a diversidade cultural é, para o gênero humano, tão necessária como a diversidade biológica para os organismos vivos. Neste sentido, constitui o patrimônio comum da humanidade e deve ser reconhecida e consolidada em beneficio das gerações presentes e futuras. (UNESCO Declaração Universal sobre a Diversidade Cultural, 2002, p. 3)

Era preciso compreender os vestígios do passado e as diferentes formas de expressões culturais no processo histórico da humanidade em partes distintas do planeta, que deveriam ser preservados e legados às gerações vindouras. Nessa perspectiva, a cultura passou a ser um dos elementos do marketing turístico de diversas localidades e regiões. A expansão da classe média, em alguns países, acompanhada de níveis educacionais mais elevados, impulsionou o turismo cultural, como também os investimentos, mais intensos em serviços e atividades culturais. (MINISTÉRIO DO TURISMO Plano Nacional de Turismo, 2011-2014, p. 34)

Os estudiosos debatiam que o turismo cultural também deveria ser visto como uma forma de lazer e também de relaxamento e de vivência de novas experiências culturais. Manuel Leal Pedrosa entendia que o turismo cultural era responsável por unir "a ideia de viajar e visitar a um acto de conhecimento que nos é proporcionado pelo encontro directo e pessoal com as diversas expressões de cultura de um povo ou país". (PEDROSA, [s. d.], p. 299-311) Por conseguinte, os museus eram um dos principais locais visitados pelos turistas culturais. Os monumentos históricos, igrejas, galerias, atrações artísticas e festivais eram outros locais e atividades procurados pelos turistas. Se esses espaços constituíam pontos importantes do turismo, era 
fundamental que os mesmos tivessem políticas de manutenção e preservação. (BOYER, 1999)

As transformações observadas nas últimas décadas do século XX também sinalizavam para o aumento do número de turistas que praticavam o turismo cultural. Greg Richards, especialista no assunto, entendia que o desenvolvimento de roteiros temáticos tinha recebido impulso, graças ao turismo cultural o qual conquistara maior crescimento no mercado turístico europeu. Richards salientava que, nos últimos anos, cresceram as classificações de atrações turísticas como culturais, o que tinha favorecido a elaboração de roteiros temáticos. (RICHARDS, 1998, p. 106) Além disso, tinha ocorrido um aumento da oferta de bens e serviços culturais. (SACNHO, 2001, p. 79-102) Para Richards, era possível estabelecer existência de quatro matrizes presentes na definição de turismo cultural. Os quatro tipos são: as definições derivadas do turismo baseado nos recursos (oferta); as definições motivacionais, baseadas na demanda e nos motivos alegados pelos turistas em viajar; as definições experimentais ou conceituais, baseadas no significado da atividade; e as definições operacionais, baseada nas medições feitas pelos sistemas turísticos. (MCKERCHER, 2002, p. 29-38)

A maioria dos turistas que se deslocam consomem produtos culturais, pois, na maioria das cidades, há sempre ofertas como: museus, monumentos, templos religiosos, parques arqueológicos e naturais, festas populares, artesanato, exposições fixas e temporárias, eventos, dentre outros atrativos. Podemos notar que a oferta cultural é diversa e heterogênea e pode ser encontrada com facilidade em grandes centros urbanos. Concordamos com Fábio Garcia Reis quando afirma que:

O turismo cultural deve ser considerado como uma atividade em que o deslocamento ocorre para lugares em que a motivação é a busca do conhecimento, da interação, da informação, da curiosidade cultural, dos costumes, da tradição e da identidade. Seus fundamentos são o elo entre passado e presente, o contato e a convivência com o legado cultural, com tradições que foram influenciadas pela dinâmica do tempo, mas que permanecem, com as formas de arquitetura $e$ construções de referência histórica, como herança de civilizações, com a busca da identidade, nem sempre percebida pelas pessoas, pois a modernidade transformou os padrões de comportamento. Representa a possibilidade de revitalização do patrimônio, de revigoramento das tradições, da redescoberta de comportamento que foram suplantados pelo mundo moderno e da ressignificação da cultura. (REIS, 2003, p. 47)

Ficava evidente que o turismo cultural abrange também outros produtos como: espetáculos, manifestações culturais, gastronomia, museus, monumentos, práticas religiosas, etc. Para Swarbrooke, há infinidade de tipos de recursos de turismo cultural, sendo que este pode ser definido, em termos gerais, como: "qualquer tipo de turismo inclui o turismo cultural se está motivado pelo desejo de observar, aprender e participar da cultura do destino turístico". (SWARBROOKE, 1996, p. 227-255) Como afirmamos anteriormente, o crescente interesse pela cultura e as melhores condições de formação e educação do homem permitiram que os elementos culturais conquistassem um maior espaço no turismo, transformando-se num segmento de mercado promissor, estimulado por uma procura ascendente. (PÉREZ, 2009, p. 109)

Os europeus, conforme o registro da Comissão Europeia, têm escolhido cada vez mais o turismo cultural, principalmente após a criação da Comunidade Europeia, que permitiu a formação de uma rede de cidades, que compartilhavam entre si os interesses e visitas dos turistas. Este movimento ascendente se deveu ao crescimento da expectativa de vida, ao aumento do rendimento disponível para algumas camadas da população europeia, as facilidades de circulação, a melhoria das redes de transporte, a uma conjuntura política e 
econômica favorável. Além disso, há a ampliação da oferta de diferentes atividades culturais nos grandes centros, favorecendo o desenvolvimento do turismo cultural urbano. (HENRIQUES, 2003, p. 111) É bom destacar que o turismo da terceira idade também estimulou as viagens culturais, particularmente para locais classificados como patrimônio mundial. (SILVA, 2002, p. 21-68)

Pode-se notar também que o desenvolvimento de produtos turísticos baseados no patrimônio histórico, bem como outros tipos de atrações como: a gastronomia, a arte, as tradições populares, a religião, a dança, os eventos de recreação impulsionaram o segmento e se intensificaram nas últimas três décadas. Nessa perspectiva, o espaço urbano emergiu como um destino turístico extremamente atraente por possuir um amplo caráter cultural, por si só, ou como um complemento de outras ofertas turísticas, o que favoreceu novos investimentos no setor fossem realizados.

Dessa maneira, a cultura passou a ser utilizada como um elemento fundamental para o desenvolvimento turístico. Os indivíduos, ao se deslocarem, desejam conhecer outros modos de vida, costumes e tradições; desejam também usufruir de equipamentos culturais. Isso deu ensejo a uma nova dimensão para o turismo cultural, que cresceu junto com o próprio processo de preservação das culturas ameaçadas pelo movimento de pressão da globalização cultural. Também deve-se notar que as novas tecnologias e a circulação de informação propiciaram maior conscientização sobre a cultura e o meio ambiente. Este processo modificou a percepção humana em relação à cultura e às interações com o mundo e gerou maiores motivações para viajar.

A reunião realizada em outubro de $2003 \mathrm{em}$ Barcelona, tendo como tema Cultural Tourism: Globalising the local - localising the global colocou em evidência a questão da globalização da cultura e a "culturalização" do turismo. O encontro problematizou como a cultura era consumida, alertando para o fato de que esta fazia parte de um processo de aprendizagem que permitia conhecer tanto a cultura do outro, como também promovia uma reavaliação da própria cultura do turista. Outro consenso dos estudiosos era que o turista cultural tinha liberdade de fazer a sua própria interpretação sobre o sentido do consumo da cultura. (MURTA, 2009, p. 137-162) Isso permite afirmar que o turismo cultural possibilitava o encontro e a interação de culturas, de forma que o turista tivesse a possibilidade de compreender a vivência dos habitantes de uma localidade, compreendendo os valores que fazem parte desse universo. (TRONCOSO; ALMIRÓN, 2005, p. 62) Essa prática de turismo reforçava os elos de identidade cultural local ou regional, valorizando seus elementos, ao mesmo tempo em que estimulava o envolvimento da população local e conduzia a um projeto de transformação. Não podemos esquecer que o patrimônio cultural, antes de ser um "atrativo turístico, é fator de identidade cultural e de memória das comunidades, fonte que as remete a uma cultura partilhada, a experiências vividas, a sua identidade cultural e, como tal, deve ter seu sentido respeitado". (MINISTÉRIO DO TURISMO - Turismo Cultural, [s.d.], p. 9)

O turismo de motivação cultural trouxe vantagens à preservação do patrimônio arquitetônico, pois ajudou a dar novos usos para antigas edificações. Ele favoreceu a formação de entidades de valorização do patrimônio, bem como estimulou o desenvolvimento econômico dos locais de visita, devido à intensificação da atividade. (HENRIQUES, 2003, p. 82-88) Conforme destaca Margarita Barreto a revitalização do patrimônio tem contribuído para a: "recuperação de identidades locais ameaçadas em todas as partes do mundo pelo avanço de uma única cultura hegemônica, que se impôs nas últimas décadas na música, no vestuário, na alimentação, nas formas de lazer e de consumo". (BARRETO, 
2000, p. 44) Contudo, deve-se tomar cuidado para que o turismo não transforme o patrimônio cultural em simples mercadoria. Esta situação, quando ocorre, faz com que o turismo cultural não represente de fato aprendizagem ou educação aberta para o relacionamento entre culturas. (PÉREZ, 2009, p. 112)

A OMT, em 2005, empreendeu um estudo para classificar os lugares e seus produtos culturais estabeleceu três categorias de produtos: patrimônio; patrimônio + arte; patrimônio + arte + empresas de lazer. Essas categorias partiam do pressuposto de que: patrimônio deveria ser entendido como o produto cultural predominante relacionado ao passado. A arte, por sua vez, corresponderia ao conjunto de artes cênicas e visuais contemporâneas do lugar. Por fim, as empresas de lazer eram todas aquelas que tivessem como proposta comercializar a cultura contemporânea participativa. (OMT El Turismo Urbano y la Cultura, 2005)

Nesse mesmo estudo, a OMT distinguiu diferentes 6 tipos de cluster a partir do cruzamento do produto cultural (patrimônio, arte e empresas de lazer) com o tipo de localidades onde se oferece os produtos culturais (aldeia, vila, cidade e área metropolitana).

Em 2006, o Ministério do Turismo do Brasil, acompanhando os estudos e debates internacionais, elaborou as Orientações Básicas de Turismo Cultural. Em se considerando a diversidade da oferta turística mundial e a necessidade de consolidação de novos segmentos turísticos, era preciso adotar práticas de planejamento e gestão eficazes, a fim de que tanto da atividade turística como a população local fossem beneficiadas. O texto alertava para a necessidade do conhecimento aprofundado sobre cada segmento.

O documento reconhecia que o Brasil possuía diferentes recursos naturais e culturais os quais permitiam a estruturação de novos produtos turísticos, que deveriam ter como objetivo promover e preservar os ele- mentos culturais. Reconhecia-se que todos os povos eram detentores de cultura, entendendo que cultura significa "a totalidade ou o conjunto da produção, de todo o fazer humano de uma sociedade, suas formas de expressão e modos de vida". A relação cultura e turismo está alicerçada em dois pilares:

o primeiro é a existência de pessoas motivadas em conhecer culturas diversas $e$ o segundo é a possibilidade do turismo servir como instrumento de valorização da identidade cultural, da preservação e conservação do patrimônio, e da promoção econômica de bens culturais. (MINISTÉRIO DO TURISMO - Turismo Cultural: orientações básicas, Brasil, 2006, p. 9)

Numa ação conjunta do Ministério do Turismo, do Ministério da Cultura e do IPHAN, chegou-se a uma definição que turismo cultural, deveria ser entendido como: "as atividades turísticas relacionadas à vivência do conjunto de elementos significativos do patrimônio histórico e cultural e dos eventos culturais, valorizando e promovendo os bens materiais e imateriais da cultura". O turismo cultural estava diretamente ligado à motivação do turista em interagir e vivenciar experiências culturais diversas. Por conseguinte, o turista poderia estabelecer tipos de relação diferentes com a cultura, a saber:

a primeira refere-se ao conhecimento,
aqui entendido como a busca em apren-
der e entender o objeto da visitação; a
segunda corresponde a experiências par-
ticipativas, contemplativas e de entreteni-
mento, que ocorrem em função do objeto
de visitação. (MINISTÉRIO DO TURIS-
MO - Turismo Cultural: orientações bá-
sicas, Brasil, 2006, p. 11)

O Ministério do Turismo, nas suas orientações básicas sobre o turismo cultural, entende que os patrimônios histórico e cultural é composto pelos:

bens de natureza material e imaterial que expressam ou revelam a memória e a 
identidade das populações e comunidades. São bens culturais de valor histórico, artístico, cientifico, simbólico, passíveis de tornarem-se atrações turísticas: arquivos, edificações, conjuntos urbanisticos, sítios arqueológicos, ruínas; museus e outros espaços destinados à apresentação ou contemplação de bens materiais e imateriais; manifestações como música, gastronomia, artes visuais e cênicas, festas e celebrações. (MINISTÉRIO DO TURISMO - Turismo Cultural: orientações básicas, Brasil, 2006, p. 9)

Entende-se também que eventos culturais como aqueles que englobavam manifestações de caráter temporário, que poderia incluir "eventos gastronômicos, religiosos, musicais, de dança, de teatro, de cinema, exposições de arte, de artesanato e outros". (MINISTÉRIO DO TURISMO - Turismo Cultural: orientações básicas, Brasil, 2006, p. 11)

O Ministério do Turismo esclarecia no documento que o turismo cultural poderia ocorrer por motivos diferentes, tais como: religiosos, místicos, esotéricos, cívicos, étnicos e gastronômicos, os quais poderiam constituir outros segmentos turísticos, englobados pelo turismo cultural. Essas definições contribuíram de maneira acentuada na definição de políticas de gestão estratégica, que viesse a nortear o crescimento, ao mesmo tempo em que se garantia a preservação dos recursos culturais e naturais.

O Ministério do Turismo, considerando os trabalhos empreendidos no México sobre a viabilidade do turismo cultural, passou a entender que poderiam existir dois tipos de turistas:

a) aqueles com interesse específico na cultura, isto é, que desejam aprofundarse na compreensão das culturas visitadas e se deslocam especialmente para esse fim; b) aqueles com interesse ocasional na cultura, possuindo outras motivações que $o$ atraem ao destino, relacionando-se com a cultura apenas como uma opção de lazer. (MINISTÉRIO DO TURISMO - Turismo Cultural: orientações básicas, Brasil, 2006, p. 13-14)

Constituíam os principais atrativos do turismo cultural:
Sítios históricos - centros históricos, qui- lombos; Edificações especiais - arquite- tura, ruínas; Obras de arte; Espaços e instituições culturais - museus, casas de cultura; Festas, festivais e celebrações locais; Gastronomia típica; Artesanato e produtos típicos; Música, dança, teatro, cinema; Feiras e Mercados tradicionais; Saberes e Fazeres - causos, trabalhos manuais; Realizações artísticas - exposi- ções, ateliês; Eventos programados - feiras e outras realizações artísticas, cul- turais, gastronômicas. (MINISTÉRIO DO TURISMO - Turismo Cultural: ori- entações básicas, Brasil, 2006, p. 13-14)

Os debates sobre a questão do uso do patrimônio nas cidades avançaram em diferentes linhas nos últimos anos. Em 2012, realizou-se, em Bruges na Bélgica, a Conferência internacional sobre as oportunidades e desafios da conservação e gestão do patrimônio urbano. O crescimento e desenvolvimento das cidades inscritas no patrimônio mundial fazia com que se discutisse quais os instrumentos mais apropriados para gerar as transformações essenciais. A grande questão posta era como essas cidades poderiam continuar a manter as funções de uma cidade contemporânea sem alterar o patrimônio 5 .

Recentemente, em 2015, no XIII Congresso mundial da organização das vilas do patrimônio mundial, realizado em Arequipa no Peru, reafirmou-se o comprometimento com o patrimônio e a necessidade de estudos mais aprofundados sobre as cidades e os bens

\footnotetext{
${ }^{5}$ Sobre a questão ver: Organización de las Ciudades del Patrimonio Mundial (OCPM) - Villes du patrimoine mondial au 21 ième siècle Conférence internationale sur les opportunités et défis pour la conservation et la gestion du patrimoine urbain. Disponível em:

$<\mathrm{http} / / /$ www.ovpm.org/fr/nouvelles/villes_du_patrimoine_mondial_au_21ieme_siecle_conference_internationale_sur_les>. Acesso: 11/04/2017.
} 
culturais. Em se considerando que o conceito de patrimônio era complexo, recomendava-se que reflexões transversais fossem realizadas. Era reafirmada a importância dos planos de gestão e dos planos diretores como instrumentos importantes de preservação do patrimônio. A questão da obtenção de recursos para a manutenção dos bens culturais era posta em evidência, sendo necessário considerar as realidades locais. Foi destacado que a atividade turística era um meio mais eficaz para melhorar a qualidade de vida nas cidades, o que exigia que a atividade fosse planejada, a fim de a experiência do turista fosse positiva ao visitar o local. Desafios que devem ser enfrentados nos próximos anos. (OCPM - Declaração de Arequipa, 2015)

Em suma, no que tange ao patrimônio cultural, podemos concluir que, no decorrer dos anos, um intenso debate, promovido por diferentes instituições internacionais e nacionais, processou-se sobre o assunto, gerando recomendações e legislações específicas para procedimentos de preservação, conservação, restauração dos bens e principalmente sobre o seu uso pela atividade turística. Como pudemos observar, o conceito de turismo cultural não fica restrito à ideia patrimonial, como bens materiais legados pelos ancestrais a geração presente. Ele inclui também elementos da cultura contemporânea como exposições de arte, teatro, música, festas populares, festas religiosas, feiras gastronômicas dentre outras atividades que podem ocorrer em diferentes espaços, inclusive religiosos. Outras definições mais amplas foram elaboradas no sentido de buscar uma precisão do termo, entendendo turismo cultural como uma atividade relacionada com a herança intelectual e artística de uma região; ou, que como o movimento temporário que algumas pessoas realizam deslocando-se de suas residências, com a intenção de satisfazer as suas necessidades culturais. Neste processo o elemento chave é a educação patrimonial, a qual deve ser guiada pela máxima "conhecer para preservar, preservar para conhecer".

\section{Referências}

BARRETO, Margarita. Turismo e Legado Cultural. Campinas: Papirus, 2000.

BOURDIEU, Pierre. La Distinction - critique sociale du jugement, Paris: Les Éditions de Minuit, 1979.

BOYER Marc. Histoire du tourisme de masse. Paris: PUF, 1999.

BOYER, Marc. Histoire de l'invention du tourisme. Paris: L'aube, 2000.

CAMARGO, Patrícia. “Os impactos do turismo cultural”. In: CAMARGO, Patrícia de e CRUZ, Gustavo da. Turismo cultural. Ilhéus: Editus, 2009, p. 69-88.

CHOAY, F. A alegoria do patrimônio. São Paulo: Estação Liberdade/Unesp, 2001.

Decreto Lei $\mathrm{n}^{\circ}$. 2807, de 21 de outubro de 1998. Atualmente é válido o Decreto $\mathrm{n}^{\circ} 4.811$, de 19 de agosto de 2003.

DELORS, Jacques. Educação: Um Tesouro a Descobrir. São Paulo: UNESCO/MEC/ Cortez, 1999.

FRENTRESS, J.; WICKHMAN, C. Memória social. Lisboa: Teorema, 1994.

GRUNBERG, Evelina. Manual de atividades práticas de Educação Patrimonial. Brasília: IPHAN, 2007.

HENRIQUES, Claudia. Turismo Cidade e Cultura. Lisboa: Edições Silabo, 2003.

HORTA, Maria de Lourdes; GRUNBERG, Evelina e MONTEIRO, Adriane Queiroz. Guia Básico da Educação Patrimonial. Rio de Janeiro: Museu Imperial/DEPROM-IPHAN-MINC, [s.d.].

ICOMOS - Carta para a Preservação do Patrimônio do Quebec - Declaração de Deschambault - 1982.

ICOMOS - Declaração de Querétaro, 1993. 
IPHAN - Carta de Fortaleza - 1997.

IPHAN - Carta de Mar del Plata sobre patrimônio intangível, 1997.

LANGLEY, Andrew. September 11: Attack on America. Minneapolis: Compass Point Books, 2006.

MCKERCHER B. "Towards a Classification of Cultural Tourists". In: International Journal of Tourism Research. 2002, 4, p. 29-38.

MINISTÉRIO DO TURISMO - Plano Nacional de Turismo (PNT) - Turismo no Brasil 2011-2014.

MURTA, Stela Maris. "Interpretar o patrimônio: um desafio para o turismo cultural”. In: CAMARGO, Patrícia de e CRUZ, Gustavo da. Turismo cultural. Ilhéus: Editus, 2009, p. 137-162.

OCPM - Declaração de Arequipa, 2015.

OMT - CódigoMundial de Ética do Turismo, 1999.

OMT - Carta do Turismo Sustentável - Declaração de Lanzarote. Ilhas Canárias/Espanha: OMT, 1995.

PEDROSA, Manuel Leal "Igrejas e Turismo Cultural”. In: IPPAR - Património Classificado, Actas dos Encontros promovidos pelo IPPAR e pela UCP, p. 299-311.

PÉREZ, Xerardo Pereiro. Turismo cultural - uma visão antropológica. Tenerife/Espanha: ACAy Pasos, 2009, p. 109.

REIS, Fábio José Garcia (org.). Turismo - uma Perspectiva Regional. Taubaté: Cabral, 2003.

RICHARDS, Greg.Cultural Tourism in Europe. Wallingford: CAB International, 1996.

RICHARDS, Greg. "Cultural tourism in Europe: recent developments". In: European Congress about Cultural Itineraries and Thematic Routes. Logroño: Fundación Cajá Rioja, 1998.

RICHARDS, Greg. "Turismo Cultural: padrões e implicações”. In: CAMARGO, Patrícia de e CRUZ, Gustavo da. Turismo cultural. Ilhéus: Editus, 2009, p. 25-48.

RICHARDS, Greg. Cultural Attractions and Cultural Tourism. Wallingford: CAB International, 2001.

RICHARDS, Greg. Cultural Tourism: Global and local perspectives. New York: Haworth Press, 2006.

SANCHO, Amparo (Dir.). Introdução ao Turismo - OMT. São Paulo: Roca, 2001.

SILVA, Fátima Sueli de Souza. Turismo e psicologia no envelhecer. São Paulo: Roca, 2002.

SIMÕES, Maria de Lourdes Netto. "Identidade cultural e turismo: a literatura como agenciadora de trânsitos". In: CAMARGO, Patrícia de e CRUZ, Gustavo da. Turismo cultural. Ilhéus: Editus, 2009, p. 49-67

SWARBROOKE, J. 1996. "Towards a sustainable future for cultural tourism: a European perspectiva". In: ROBINSON, M. et al. (ed.) Tourism and Culture: managing cultural resources for the tourist. Great Britain: The Centre for travel and Tourism in association with Bussiness Education Publisher, 1996, p. 227-255.

SWARBROOKE, John. Turismo sustentável: turismo cultural, ecoturismo e ética. São Paulo: Aleph, 2000.

TRONCOSO, Claudia A.; ALMIRÓN, Analía V. "Turismo y patrimonio - Hacia una relectura de sus relaciones". In: Aportes y transferencias, Mar del Plata: Universidade Nacional de Mar del Plata - Argentina, año/vol., 1 $\mathrm{n}^{\mathrm{o}} 09,2005$, p. 62.

VASCONCELLOS, Camilo de Mello. Turismo e Museus. São Paulo: Aleph, 2006. 